Supplementary Information for

\title{
Convection-Enhanced Delivery of Solutes to the Brain Using Electrokinetic Transport
}

Amir H. Faraji, Andrea S. Jaquins-Gerstl, Alec C. Valenta, Yanguang Ou, and Stephen G. Weber

Corresponding Author: Stephen G. Weber

Email: sweber@pitt.edu

This PDF file includes:

Experimental Data Figures S1 to S6

Comsol Calculation Figures S7-S9

Boundary Conditions and Parameters for COMSOL Tables S1 to S7 


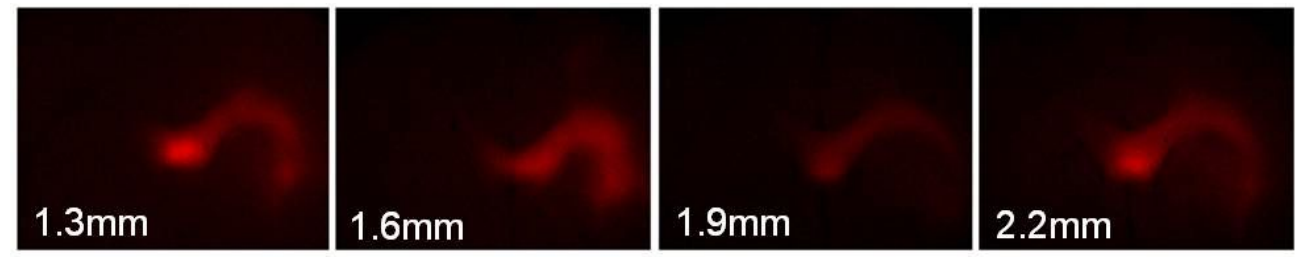

Fig. S1. A collection of fluorescent in vivo images demonstrating electrokinetic transport may be directed along anatomical structures within the tissue. Once the infusate reached the corpus callosum, flow occurs along the horizontal track of the axons in this region. Numbers correspond to bregma (anterior to bregma). Slices were $300 \mu \mathrm{m}$ in thickness. 


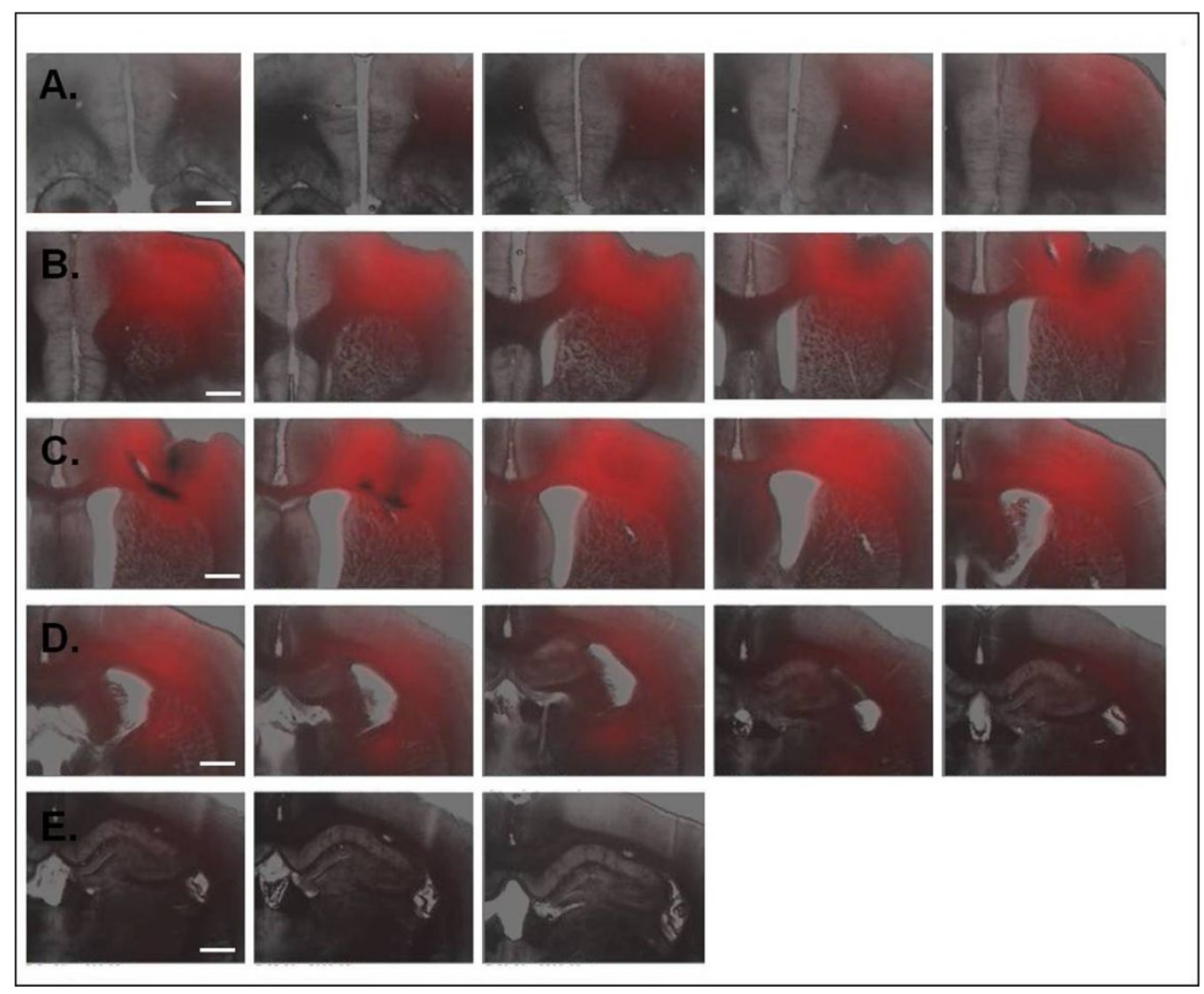

Fig. S2. An example of directionality in vivo of $\mathrm{Ru}(\mathrm{bpy}){ }_{3}{ }^{2+}$, from the prefrontal cortex to the striatum with $75 \mu \mathrm{A}$ applied for 5 hours. Fluorescent images are superimposed onto bright field images. Row C, second column (C2) represents the plane of the infusion cannula and B5 represents the plane of the counter cannula. Slices were cut to $300 \mu \mathrm{m}$ and sequentially imaged; starting with row A to E. Scale bar is $1,000 \mu \mathrm{m}$. 

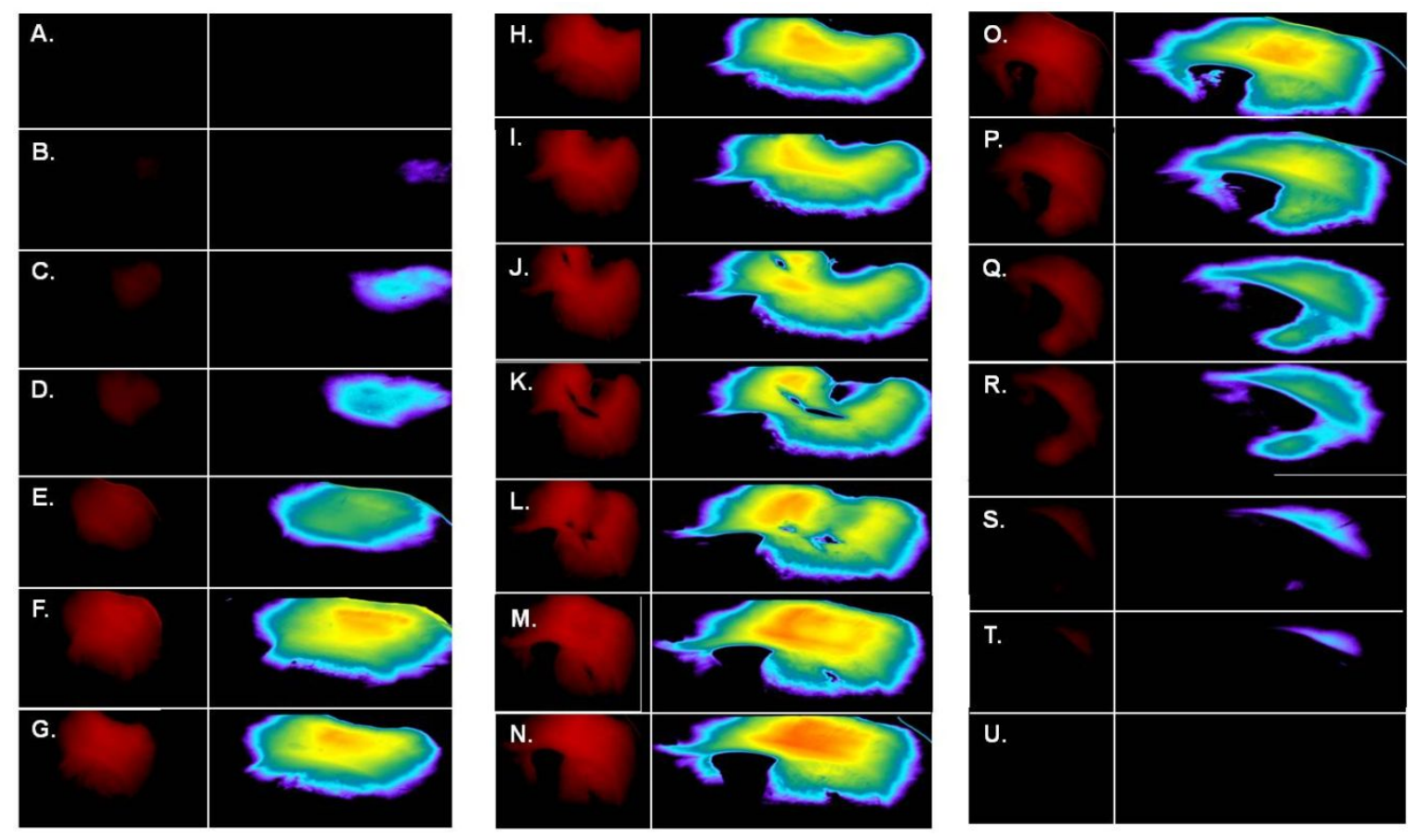

Fig. S3. ECED of Ru(bpy) ${ }_{3}{ }^{2+}$ in vivo into the prefrontal cortex (top of panel L) to the striatum (panel K) with $75 \mu \mathrm{A}$ applied for 5 hours from a $100 \mu \mathrm{m}$ inner diameter fused silica infusion cannula. Fluorescent microscopy images are in panels to the left and their corresponding surface intensity plots are to the right. Although, the $\mathrm{Ru}(\mathrm{bpy})_{3}{ }^{2+}$ molecules tend to move along the corpus callosum (images $\mathrm{H}-\mathrm{J}$ ), they also move into the striatum as well (images $\mathrm{K}-\mathrm{R}$ ). $\mathrm{L}$ represents the plane of the infusion cannula and $\mathrm{K}$ represents the plane of the counter cannula. Slices were cut to $300 \mu \mathrm{m}$ and sequentially imaged. Scale bar is $1,000 \mu \mathrm{m}$. 

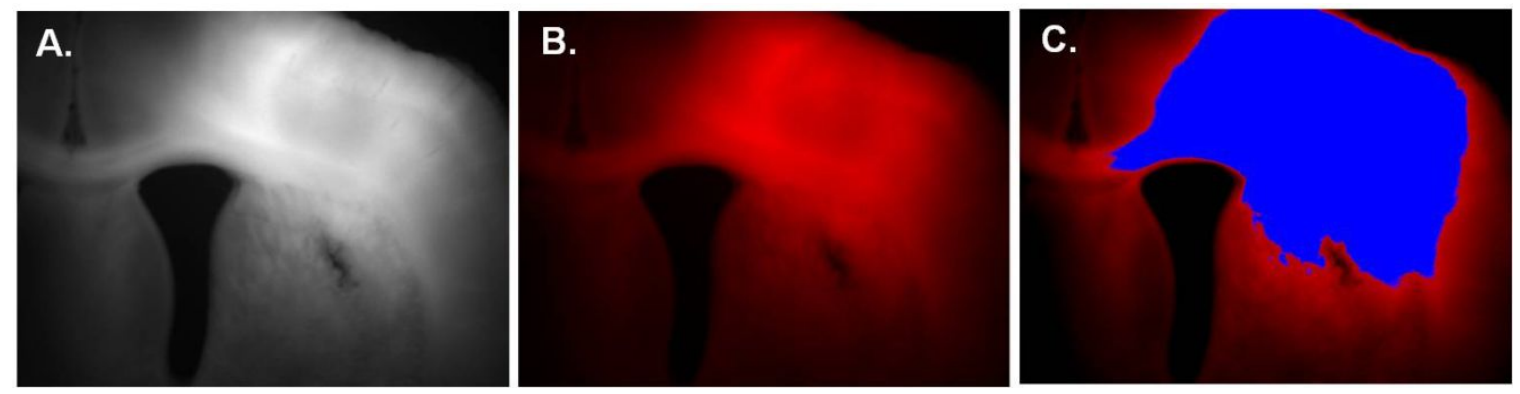

Fig. S4. An example of the thresholding process using NIS Element Advanced Research software for in vivo analysis. (A) Black and white $300 \mu \mathrm{m}$ section of brain tissue with $\mathrm{Ru}(\mathrm{bpy}){ }_{3}{ }^{2+}$. (B) Original image using an appropriate fluorescence laser line of $\mathrm{Ru}(\mathrm{bpy})_{3}{ }^{2+}$. (C) Post-thresholding image with the ROI coded in blue. Only the threshold area (blue) was used to calculate the $V_{d}$. This analysis was performed on all slices containing $\mathrm{Ru}(\mathrm{bpy})_{3}{ }^{2+}$, and pixels outside this region were not considered in the calculation of $V_{d}$ with this methodology. 

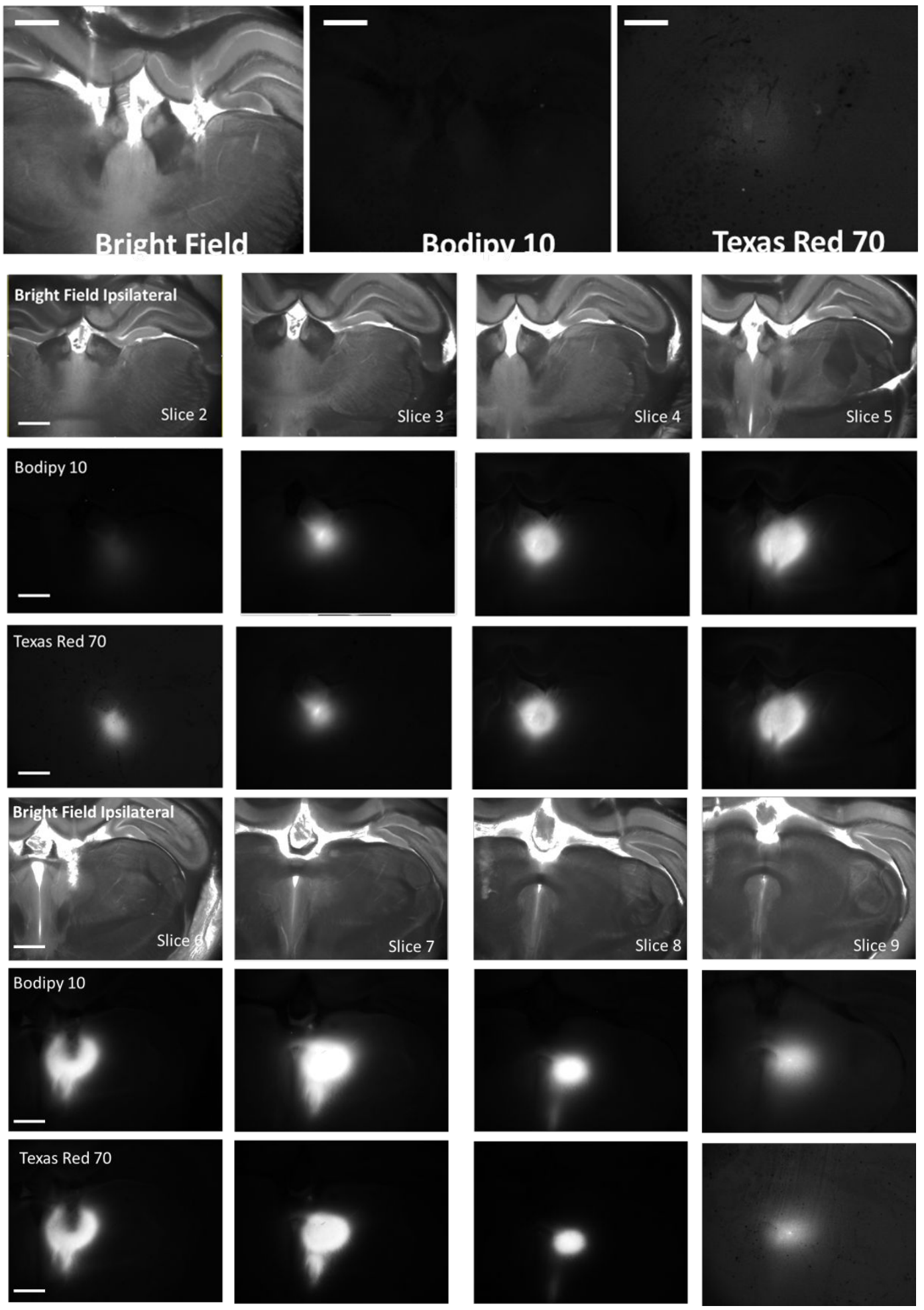

Fig. S5. Electroosmotic infusion of Bodipy-labeled dextran (10 kDa) and Texas Red-labeled dextran $(70 \mathrm{kDa})$ for $45 \mathrm{~min}$ at $25 \mu \mathrm{A}$ from a $100 \mu \mathrm{m}$ inside diameter fused silica cannula into the thalamus of an adult male rat. Row 1. Brightfield and fluorescence images from controls (current $=0$ ). Blue arrowhead points at cannula tracks. Rows 2a-c: From anterior to posterior, coronal slices were 300 


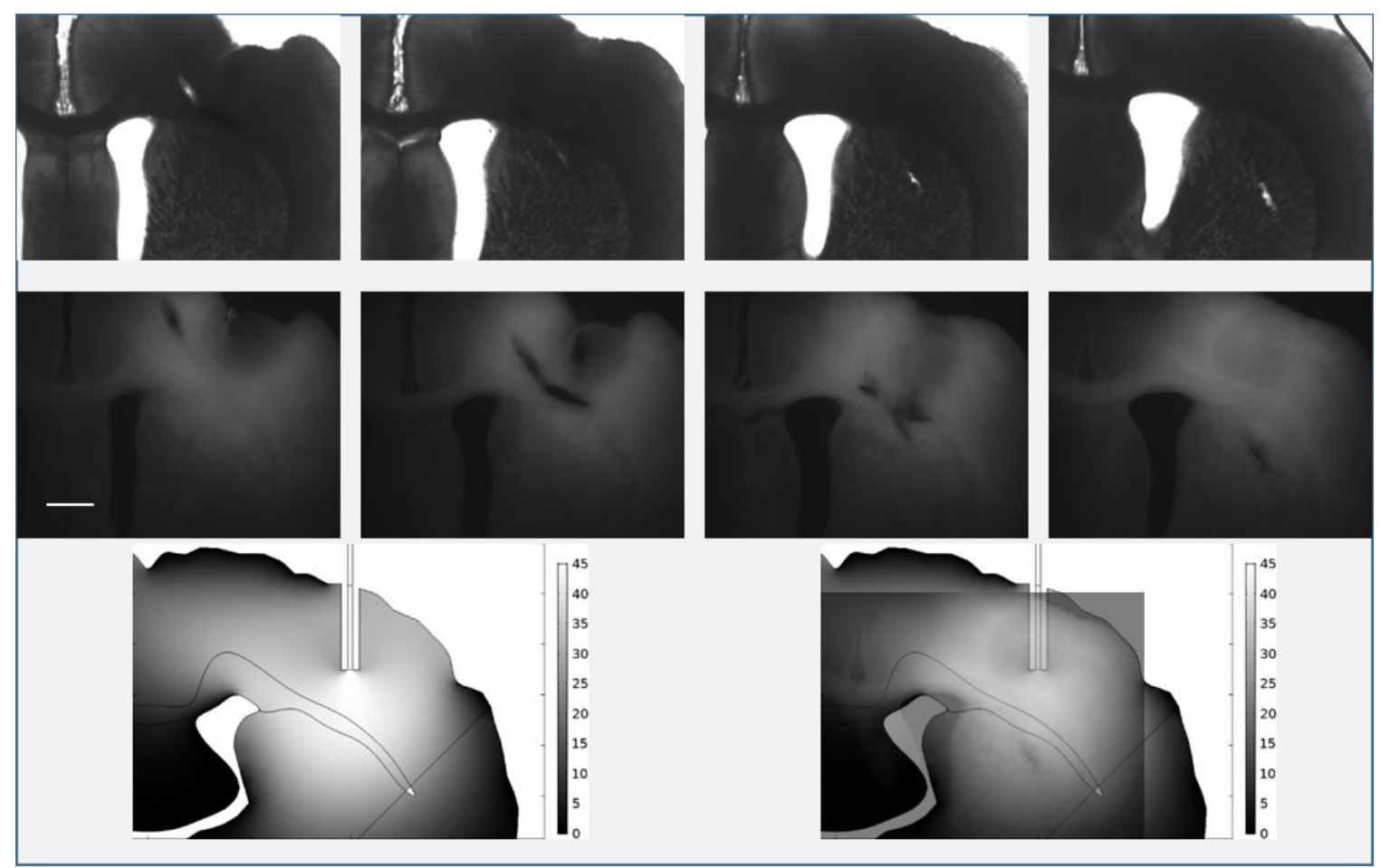

Fig. S6. Reproduction of Fig. 5 in the text without enhanced contrast in the experimental images. 


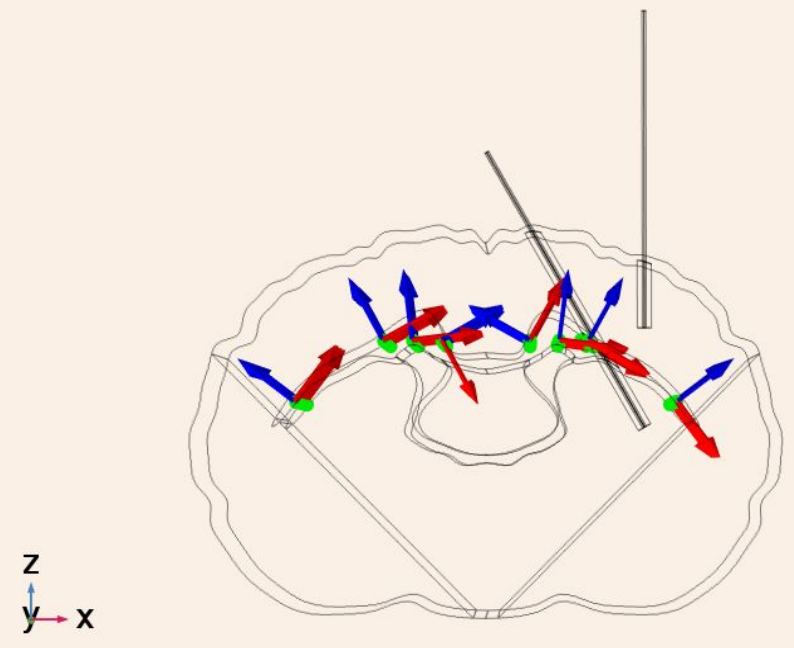

Fig. S7. Solution to the curvilinear coordinate systems module, in which the vector field $v$ was determined. The vector field $v$ follows the curvature of the corpus callosum. 


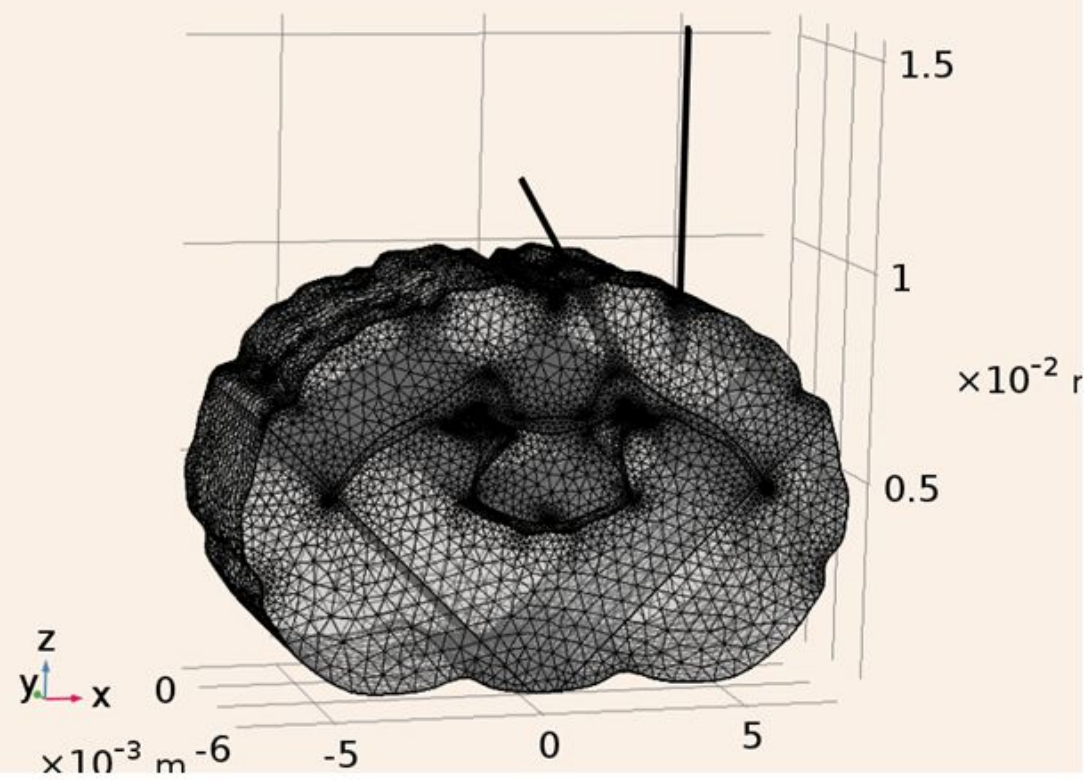

Fig. S8. Mesh elements for the anistropic electrokinetic convention-enhanced delivery (ECED) model. The geometry is finely meshed in the capillaries, at the site of infusion, and in the corpus collosum. 


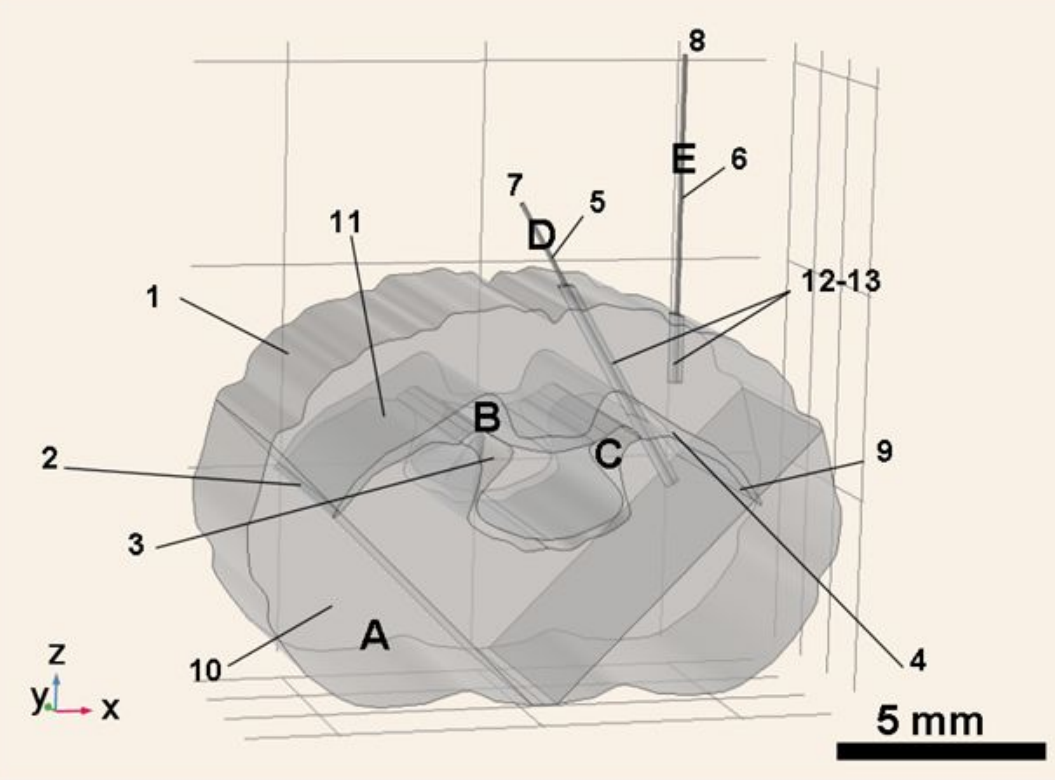

Fig. S9. 3D geometry for ECED model. A- non-corpus callosum brain tissue, B - corpus callosum, C - ventricles, D counter capillary, E - infusion capillary. All of the boundaries are labeled as numbers and the domains are labeled as letters. Boundaries $2 \& 9$ indicate boundaries at either end of the corpus callosum. These are important for generating a curvilinear coordinate system for anistropic studies. Boundaries $4 \& 10$ have equivalent boundaries on the other side of the geometry and are used to generally denote boundaries on both sides. Boundary 11 indicates the walls of the corpus callosum domain. Boundaries 12 and 13 indicate the outer walls of the capillaries that are in contact with the tissue. 
Table S1. Boundary conditions for Electric Currents module in COMSOL Multiphysics v5.3 for ECED model. $J$ is the current density, $\sigma$ is the conductivity, $V$ is the voltage drop, $J_{e}$ is the external current density source, $n$ is the normal vector, and $I_{0}$ is the applied current.

\begin{tabular}{|c|c|c|}
\hline Boundary/Domain & Boundary condition & Equation, if applicable \\
\hline $\mathrm{A}, \mathrm{D}-\mathrm{F}$ & $\begin{array}{l}\text { Current conservation using } \\
\text { global coordinate system }\end{array}$ & $\nabla \cdot \stackrel{\vec{J}}{=}=-\nabla \cdot\left(\sigma \nabla V-\stackrel{\breve{J}}{J}_{e}\right)=0$ \\
\hline $\mathrm{B}$ & $\begin{array}{l}\text { Current conservation using } \\
\text { curvilinear coordinate system }\end{array}$ & $\nabla \cdot \stackrel{u}{J}=-\nabla \cdot\left(\sigma \nabla V-\stackrel{u}{J}_{e}\right)=0$ \\
\hline $1,3-6,10$ & Electric insulation & $\stackrel{\Downarrow}{n} \cdot \vec{J}=0$ \\
\hline 7 & Terminal, current & $\begin{array}{c}i=i_{0}, \text { where } \\
i_{0}=-75 \mu \mathrm{A}\end{array}$ \\
\hline 8 & Ground & $V=0$ \\
\hline
\end{tabular}


Table S2. Boundary conditions for curvilinear coordinate system. The coordinate system settings are set with respect to the $y$-axis. This coordinate system is setup so that the normal Cartesian coordinate system orients with respect to the curvature of the corpus callosum. This module computes the vector field $v$.

\begin{tabular}{|c|c|c|}
\hline Boundary/Domain & Boundary condition & Equation, if applicable \\
\hline B & Diffusion method & $\nabla \cdot(\nabla U)=0$ \\
& & $v=\frac{-\nabla U}{|-\nabla U|}$ \\
\hline 11 & & $-n \cdot \nabla U=0$ \\
\hline 2 & Wall & $\begin{array}{c}\text { Condition on: value } \\
\mathrm{U}_{0}=1 \mathrm{~m} \text { (default) }\end{array}$ \\
\hline 9 & Inlet & $\mathrm{U}=0$ \\
\hline
\end{tabular}


Table S3. Boundary conditions for Free and Porous Media Flow for EOPPP model. $u$ is the superficial velocity, $\mu_{\mathrm{eo}}$ is the electroosmotic mobility, $E$ is the electric field, $P$ is the pressure, $L_{m}$ is the length of the capillary unaccounted for in the model geometry (the capillaries were truncated to save on computation time), $\eta$ is the dynamic viscosity, $\Delta u$ is the difference between the wall velocity and average velocity, $a$ is the radius of the capillary, and $f_{0}$ is the normal stress.

\begin{tabular}{|c|c|c|}
\hline Boundary & Boundary condition & Equation, if applicable \\
\hline $2,9,12-13$ & No slip walls & $\vec{u}=0$ \\
\hline $5-6$ & Moving walls & 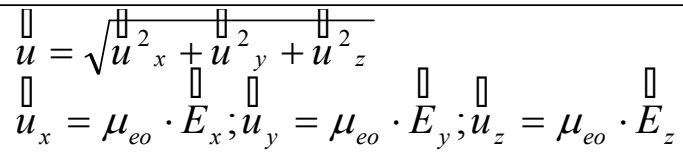 \\
\hline 8 & $\begin{array}{c}\text { "Hagen-Poiseuille } \\
\text { inlet" }\end{array}$ & $\Delta P=\frac{8 L_{m} \eta \Delta u}{a^{2}}$ \\
\hline 7 & $\begin{array}{c}\text { "Hagen-Poiseuille } \\
\text { outlet" }\end{array}$ & $\Delta P=\frac{8 L_{m} \eta \Delta u}{a^{2}}$ \\
\hline $1,3,4,10$ & Open boundary & $f_{0}=0$ \\
\hline
\end{tabular}


Table S4. Boundary conditions for Transport of Diluted Species module for EOPPP model. $\mathrm{N}$ is the flux, $\mathrm{c}$ is the concentration at any time $t, c_{0}$ is the initial concentration, and $D$ is the diffusion coefficient.

\begin{tabular}{|c|c|c|}
\hline Boundary/Domain & Boundary condition & Equation, if applicable \\
\hline $2,5,6,9,12,13$ & No flux & $-\stackrel{U}{n} \cdot \stackrel{\sqcup}{N}=0$ \\
\hline 7 & Flux 1 & $\stackrel{u}{N}=\stackrel{\Downarrow}{n} \cdot(c u-D \nabla c)$ \\
\hline 8 & Flux 2 & $\stackrel{\vec{N}}{N}=\stackrel{U}{n} \cdot(c u-D \nabla c)$ \\
\hline 8 & Concentration & $\mathrm{c}=\mathrm{c}_{0 ;} \mathrm{c}_{0}=45 \mathrm{mM}$ \\
\hline $1,3,4,10$ & Open boundary & 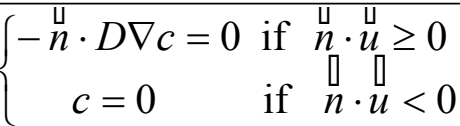 \\
\hline A, B, D & Initial values & $\mathrm{c}_{0}=0$ \\
\hline $\mathrm{E}$ & Initial values & $\mathrm{c}_{0}=45 \mathrm{mM}$ \\
\hline
\end{tabular}


Table S5. General fluid and porous matrix properties for ECED and pressure-driven CED.

\begin{tabular}{|c|c|c|}
\hline Domain(s) & Property & Value \\
\hline \multirow[t]{4}{*}{$\mathrm{A}, \mathrm{B}, \mathrm{D}, \mathrm{E}$} & Density $(\rho)$ & $1 \times 10^{3} \mathrm{~kg} / \mathrm{m}^{3}$ \\
\hline & Permittivity of water $\left(\varepsilon_{\mathrm{w}}\right)$ & $7.1 \times 10^{-10} \mathrm{~F} / \mathrm{m}$ \\
\hline & Permittivity of vacuum $\left(\varepsilon_{0}\right)$ & $8.85 \times 10^{-12} \mathrm{~F} / \mathrm{m}$ \\
\hline & Dynamic viscosity $(\eta)$ & $6.9 \times 10^{-4} \mathrm{~Pa} \mathrm{~s}$ \\
\hline \multirow[t]{2}{*}{$\mathrm{D}, \mathrm{E}$} & Conductivity $(\sigma)$ of buffer & $1.79 \mathrm{~S} / \mathrm{m}$ \\
\hline & Capillary $\zeta$-potential & $-46.5 \mathrm{mV}$ \\
\hline \multirow[t]{8}{*}{ A } & Tissue $\zeta$-potential & $-22.8 \mathrm{mV}$ \\
\hline & Electroosmotic mobility* $\left(\mu_{\mathrm{eo}}\right)$ & $5.14 \times 10^{-8} \mathrm{~m}^{2} /(\mathrm{V} \mathrm{s})$ \\
\hline & Electrophoretic mobility* $\left(\mu_{\mathrm{ep}}\right)$ & $3.34 \times 10^{-8} \mathrm{~m}^{2} /(\mathrm{V} \mathrm{s})$ \\
\hline & Effective charge density* ( $\left.\rho_{\text {eff }}\right)$ & $1166.9 \mathrm{C} / \mathrm{m}^{3}$ \\
\hline & Permeability $(\kappa)$ & $10^{-15} \mathrm{~m}^{2}$ \\
\hline & Porosity $(\varepsilon)$ & 0.2 \\
\hline & Tortuosity $(\lambda)$ & 1.61 \\
\hline & $\begin{array}{l}\text { Conductivity of tissue* } \\
\qquad \sigma^{*}=\sigma\left(\varepsilon / \lambda^{2}\right)\end{array}$ & $0.14 \mathrm{~S} / \mathrm{m}$ \\
\hline \multirow[t]{7}{*}{$\mathrm{B}$} & Tissue $\zeta$-potential & $-22.8 \mathrm{mV}$ \\
\hline & Electroosmotic mobility* $\left(\mu_{\mathrm{eo}}\right)$ & $5.14 \times 10^{-8} \mathrm{~m}^{2} /(\mathrm{V} \mathrm{s})$ \\
\hline & $\begin{array}{c}\text { Permeability }(\kappa) \\
\text { (curvilinear coordinate) }\end{array}$ & $\begin{aligned} \kappa_{\mathrm{x}}, \kappa_{\mathrm{y}}, \kappa_{\mathrm{z}}= & {[1.19,1.02,1.00](31) } \\
& \mathrm{x} 10^{-14} \mathrm{~m}^{2}\end{aligned}$ \\
\hline & Porosity $(\varepsilon)$ & 0.2 \\
\hline & $\begin{array}{c}\text { Tortuosity }(\lambda) \\
\text { (curvilinear coordinate) }\end{array}$ & $\lambda_{x}, \lambda_{y}, \lambda_{z}=[1.46,1.70,1.72]$ \\
\hline & $\begin{array}{l}\text { Conductivity of tissue* } \\
\qquad \sigma^{*}=\sigma\left(\varepsilon / \lambda^{2}\right) \\
\text { (curvilinear coordinate) }\end{array}$ & $\begin{array}{c}\sigma_{\mathrm{x}}, \sigma_{\mathrm{y}}, \sigma_{\mathrm{z}}=\underset{\mathrm{S} / \mathrm{m}}{[0.16,0.12,0.12]} \\
\end{array}$ \\
\hline & $\begin{array}{l}\text { Effective charge density* } \\
\qquad\left(\rho_{\text {eff }}\right)\end{array}$ & $\begin{array}{c}\rho_{\text {eff, }, \mathrm{x}}, \rho_{\text {eff, } y}, \rho_{\text {eff, } z}=[119,102, \\
101] \mathrm{C} / \mathrm{m}^{3}\end{array}$ \\
\hline
\end{tabular}


Table S6. Species properties.

\begin{tabular}{|c|c|}
\hline Property & Values \\
\hline $\begin{array}{c}\text { Diffusion coefficient of } \mathrm{Ru}(\mathrm{bpy})_{3}{ }^{2+} \text { in } \\
\text { free solution }\end{array}$ & $2.7 \times 10^{-10} \mathrm{~m}^{2} / \mathrm{s}$ \\
\hline $\begin{array}{c}\text { Diffusion coefficient of } \mathrm{Ru}(\mathrm{bpy})_{3}{ }^{2+} \text { in } \\
\text { non-corpus callosum tissue }\end{array}$ & $2.0 \times 10^{-11} \mathrm{~m}^{2} / \mathrm{s}$ \\
\hline $\begin{array}{c}\text { Diffusion coefficient of } \mathrm{Ru}(\mathrm{bpy})_{3}{ }^{2+} \text { in } \\
\text { corpus callosum (curvilinear coordinate) }\end{array}$ & $\mathrm{D}_{\mathrm{x}}, \mathrm{D}_{\mathrm{y}}, \mathrm{D}_{\mathrm{z}}=[2.5,1.8,1.8]$ \\
& $\times 10^{-11} \mathrm{~m}^{2} / \mathrm{s}$ \\
\hline Electrophoretic mobility of $\mathrm{Ru}(\mathrm{bpy})_{3}{ }^{2+}$ & $3.24 \times 10^{-8} \mathrm{~m}^{2} /(\mathrm{V} \mathrm{s})$ \\
\hline$c_{0}$ & $45 \mathrm{mM}$ \\
\hline
\end{tabular}


Table S7. Boundary conditions for Darcy's law module, used to calculate flow rate using pressure driven CED. 3000 Pa was chosen for the pressure boundaries because it induced a comparable flow rate in the infusion capillary as that in ECED model for $75 \mu \mathrm{A}$ current.

\begin{tabular}{|l|l|l|}
\hline Boundary/Domain & Boundary condition & Equation, if applicable \\
\hline 8 & Pressure 1 & $\mathrm{P}=3000 \mathrm{~Pa}$ \\
\hline 7 & Pressure 2 & $\mathrm{P}=-3000 \mathrm{~Pa}$ \\
\hline $1-6,9-13$ & No flow & $-\vec{n} \cdot \rho \vec{u}=0$ \\
\hline
\end{tabular}

